\title{
Kajian Eksperimen Pengukuran Suhu Matahari Menggunakan Peralatan Sederhana Sebagai Pengayaan Materi Radiasi di Tingkat SMA
}

\author{
Dinar Maftukh Fajar ${ }^{1} *$, Indi Ghozirur Rohmah ${ }^{1}$ \\ ${ }^{1}$ Program Studi Tadris Ilmu Pengetahuan Alam Fakultas Tarbiyah dan Ilmu Keguruan \\ IAIN Jember. Jalan Mataram No. 1 Kaliwates Jember \\ * E-mail: dinarfisika@gmail.com
}

\begin{abstract}
Abstrak
Tulisan ini merupakan investigasi awal yang bertujuan menganalisis (1) eksperimen pengukuran suhu permukaan matahari menggunakan peralatan sederhana; (2) eksperimen pengaruh warna terhadap peningkatan suhu pada air akibat radiasi matahari, dan (3) peluang kedua eksperimen tersebut sebagai pengayaan materi radiasi di SMA. Pengukuran suhu permukaan matahari biasanya menggunakan spektrofotometer yang tidak tersedia di sekolah, maka diperlukan pendekatan lain agar pengukuran dapat dilakukan dengan peralatan sederhana dan dapat diajarkan pada pelajaran di kelas sebagai pengayaan. Hasil analisis menemukan bahwa pengukuran suhu permukaan matahari dapat dilakukan dengan mengukur perubahan suhu per satuan waktu pada air berwarna hitam yang dipanaskan di bawah terik matahari. Dengan mendapatkan data perubahan suhu per satuan waktu, dapat diperoleh Luminosity matahari dan selanjutnya dapat didapatkan suhu permukaan matahari. Hasil eksperimen yang dilakukan pada lokasi Bandung tanggal 24 Desember 2014 dan lokasi Jember tanggal 4 Juli 2018 mengkonfirmasi hal ini. Berturut-turut dihasilkan nilai suhu permukaan matahari sebesar $6219,78 \mathrm{~K}$ dengan kesalahan 7,12\% dan 5530,14 $\mathrm{K}$ dengan kesalahan 4,2\%. Hasil eksperimen juga menunjukkan bahwa warna berpengaruh terhadap peningkatan suhu pada air akibat radiasi. Warna hitam paling signifikan karena sifat warna hitam ialah menyerap panas secara sempurna. Berdasarkan analisis kelayakan, hasil eksperimen ini layak dijadikan sebagai materi pengayaan namun dengan pertimbangan-pertimbangan tertentu.
\end{abstract}

Kata Kunci: eksperimen sederhana, suhu permukaan matahari, pengayaan, radiasi, pengaruh warna terhadap suhu

\begin{abstract}
This paper presents a preliminary investigation that aims to analyze (1) the experiment measuring the surface temperature of the sun using simple equipments; (2) the experiment of the influence of color on temperature increase of water due to solar radiation, (3) and the opportunities of both experiments as enrichment material for radiation topic at physics subject in Senior High School level. This study found that the measurement of the sun's surface temperature can be administered by measuring the temperature change per unit of time on black water heated under the sun. By getting temperature change data per unit time, solar luminosity and the sun's surface temperature can be obtained. The results of experiments conducted at the Bandung location on 24 December 2014 and the Jember location on 4 July 2018 had confirmed this hypotheses. Both experiments yielded solar surface temperature values of $6219,78 \mathrm{~K}$ with $7,12 \%$ error and $5530,14 \mathrm{~K}$ with $4,2 \%$ error, respectively. The experimental results also show that the color influences the temperature increase of water due to radiation. The most significant effect was black color because the nature of the black color is absorbing heat perfectly. Based on curriculum analysis, the results of this experiment are worthy of being used as enrichment material but with certain considerations.
\end{abstract}

Keywords: simple experiments, surface temperature of sun, enrichment, radiation, the effect of color on temperature 


\section{PENDAHULUAN}

Pembelajaran fisika berkaitan dengan dua pengertian, yaitu pembelajaran dan fisika. Pembelajaran merupakan proses belajar mengajar yang terjadi antara peserta didik dan guru yang didukung oleh sarana penunjang, media, model, dan lain-lain. Sedangkan fisika adalah ilmu yang mempelajari tentang peristiwa atau gejala alam dengan berbagai perubahan materi dan energi. Tugas guru adalah mendayagunakan segala upaya tersebut agar menghasilkan proses pembelajaran yang baik, motivatif, dan bermakna, serta mencapai standar nilai yang diharapkan (Ningrum, Mahardika, \& Gani, 2015).

Apabila proses pembelajaran telah menghasilkan standar nilai yang diharapkan, atau telah tuntas dalam menguasai suatu Kompetensi Dasar (KD) dengan membandingkan perolehan nilai peserta didik dengan Kriteria Ketuntasan Minimal (KKM), maka guru dapat memberikan materi pengayaan pada salah satu KD tersebut (Direktorat Pembinaan SMA, 2010). Pengayaan diberikan kepada peserta didik yang memiliki kemampuan yang lebih dalam belajar. Kemampuan yang lebih tersebut antara lain (1) belajar lebih cepat (2) mudah dalam menyimpan informasi, (3) memiliki rasa ingin tahu tinggi, (4) memiliki cara berpikir mandiri, (5) superior dalam berpikir abstrak, dan (6) memiliki banyak minat (Dwiretnowati, 2012).

Dalam merencanakan materi pengayaan, pertimbangan akan keaktifan siswa sangat diperlukan. Keaktifan dalam belajar fisika terletak pada dua segi, yaitu aktif dalam bertindak (hands activity) dan aktif berpikir (minds activity). Mims menyebutkan bahwa siswa akan aktif jika siswa dapat menghubungkan pengetahuan baru dengan pemahaman awal mereka. Namun menghubungkan antara keduanya dalam pembelajaran fisika tidaklah mudah (Rofiah, Rustana, \& Nasbey, 2015). Dengan mempertimbangkan keaktifan dalam bergerak dan berpikir ini, pembelajaran pengayaan diberikan untuk menambah pengetahuan peserta didik dengan informasi baru di atas kompetensi standar (Rahayu \& Hakim, 2016).

Pada tulisan ini, akan dibahas salah satu kajian pembelajaran pengayaan pada materi fisika SMA. Topik yang diambil adalah radiasi benda hitam, sesuai dengan Kurikulum Fisika Sekolah Menengah Atas (SMA) 2013 nomor 3.8 yakni: Menjelaskan secara kualitatif gejala kuantum yang mencakup sifat radiasi benda hitam, efek fotolistrik, efek Compton, dan sinar $\mathrm{X}$ dalam kehidupan sehari-hari; dan nomor 4.8 yaitu: Menyajikan laporan tertulis dari berbagai sumber tentang penerapan efek fotolistrik, efek Compton, dan sinar X dalam kehidupan seharihari (Kementerian Pendidikan dan Kebudayaan, 2013). Alasan topik ini diambil karena memiliki hubungan yang kompleks dengan topik-topik yang lain, seperti suhu dan kalor, gelombang elektromagnetik, besaran dan satuan, serta dasar-dasar astronomi sehingga diharapkan dapat memperkaya wawasan dan menguatkan pemahaman antar konsep yang sudah diajarkan.

Pada materi besaran dan satuan, telah diketahui oleh peserta didik bahwa suhu merupakan salah satu besaran pokok dengan alat ukur yang disebut termometer. Kebanyakan termometer yang dimiliki oleh laboratorium sekolah adalah termometer alkohol atau raksa dengan rentang suhu $-10^{\circ} \mathrm{C}$ hingga $110^{\circ} \mathrm{C}$ dan hanya dapat dipakai untuk mengukur suhu fluida (Hera, 2018), selain dari itu adalah termometer tanah. Hal ini menjadi sulit untuk menjelaskan bagaimana pengukuran suhu untuk benda-benda dengan rentang suhu yang lebih tinggi daripada yang dimiliki termometer-termometer tersebut. Yang kedua, benda tersebut berada pada jarak yang relatif jauh, contohnya suhu lahar gunung api, suhu logam yang berpijar, suhu matahari, bahkan suhu bintang-bintang di luar angkasa. Pada level fisika tingkat SMA, pembahasan ini hanya diajarkan sampai pada tingkat pemahaman, yakni menjelaskan jenis-jenis termometer beserta fungsinya (Pramana \& Dewi, 2014). Kemampuan mengaplikasikan pengukuran suhu yang tidak diajarkan pada kurikulum standar tergolong dalam pembelajaran pengayaan. Pada tulisan ini, penulis menyuguhkan menganalisis eksperimen pengukuran suhu permukaan matahari berdasarkan pendalaman konsep materi radiasi sebagai pembelajaran pengayaan.

Di samping pengukuran berbagai besaran atau parameter yang khas seperti jarak, massa, ukuran, kecepatan, energi, reaksi nuklir, dan sebagainya, pengukuran suhu permukaan matahari merupakan salah satu langkah awal untuk mempelajari fenomena fisis yang terjadi pada bintang tersebut (Mullan, 2009). Dengan 
mendapatkan informasi suhu matahari, peneliti dapat mengetahui struktur internal matahari dan memprediksi masa depannya (Nur, 2011).

Para astronom mengukur suhu permukaan matahari atau bintang-bintang di luar angkasa menggunakan suatu kaidah yang disebut dengan fotometri bintang. Alat ukur yang digunakan dalam kaidah ini adalah spektrometer.
Namun, cara seperti ini tidak dapat dilakukan bila tidak tersedia alat spektrometer tersebut. Dengan demikian, diperlukan pendekatan lain yang lebih efektif dan sesuai dengan ketersediaan peralatan di laboratorium.

Melalui tinjauan beberapa referensi yang berkaitan dengan konsep radiasi benda hitam, kalorimetri, dan dasar-dasar astronomi,

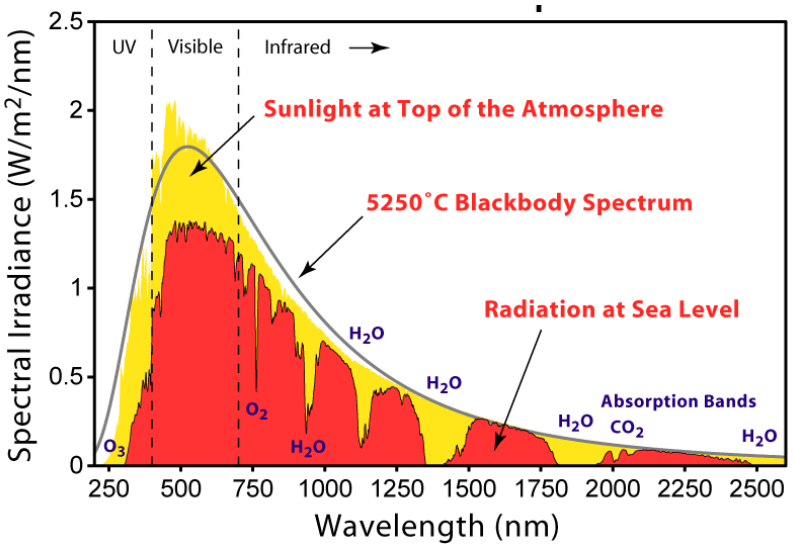

Gambar 1. Spektrum Radiasi Matahari

Cara kerja spektrometer ialah mendapatkan spektrum radiasi dari masingmasing panjang gelombang yang dipancarkan oleh suatu bintang beserta intensitasnya. Ilustrasi hasil pengukuran ini dilukiskan seperti pada Gambar 1. Bila intensitas maksimum pada suatu panjang gelombang diperoleh, maka dapat ditentukan suhu bintang tersebut dengan rumus Pergeseran Wien sebagai berikut (Halliday, Resnick, \& Walker, 2013).

$$
\lambda_{\max } T=C
$$

dengan $C=0,0028978 \mathrm{mK}$.

Misalnya, telah diketahui bahwa matahari memancarkan gelombang elektromagnetik dengan panjang gelombang yang beragam (mulai dari gelombang radio hingga sinar gamma). Tetapi melalui spektrometer, intensitas maksimum yang dipancarkan oleh matahari dideteksi pada gelombang warna kuning seperti Gambar 1 berikut ini. Panjang gelombang dengan intensitas maksimum tersebut terukur sebesar $500 \mathrm{~nm}$. Maka dengan persamaan (1), dapat dihitung suhu matahari sebesar $5795 \mathrm{~K}$ (Satterly, 1919).

Demikianlah pengukuran suhu matahari menggunakan formula pergeseran Wien (Bell, 1968; Biermann, Katz, Aho, Diaz-Barriga, James, \& Petron, Jerome, 2002; Marr \& Wilkin, 2012). pengukuran suhu permukaan matahari dapat didekati dengan mengukur kecepatan pemanasan atau pendinginan di bawah sinar matahari (Kerlin, DeSilva, Rose, \& Hasbun, 2016; Lee, Gilley, \& Caris, 1997; Perry, 1979).

Pada tulisan ini akan dipaparkan kajian eksperimen tersebut dengan memanfaatkan media air dengan diberi warna hitam yang dipanaskan di bawah sinar matahari, lalu bagaimana pengaruh warna terhadap pemanasan tersebut. Berdasarkan rancangan awal ini, peralatan yang dibutuhkan relatif sederhana dan tersedia di laboratorium sekolah. Harapan penulis, kegiatan eksperimen ini dapat dikembangkan sebagai bahan pembelajaran pengayaan pada mata pelajaran fisika di tingkat SMA.

\section{METODE}

Tulisan ini melaporkan sebuah kajian dengan metode studi pustaka tentang bagaimana suhu permukaan matahari dapat didapatkan secara teori, selain teori radiasi Max Planck dan Pergeseran Wien, yakni dengan penurunan persamaan matematis terkait dengan kecepatan pemanasan atau pendinginan suatu benda di bawah sinar matahari, kemudian melihat bagaimana hasil tersebut bila dibandingkan dengan eksperimen. 
Eksperimen yang dilakukan untuk mengkonfirmasi teori tersebut membutuhkan peralatan sebagai berikut:

(1) Air murni $100 \mathrm{~cm}^{3}$;

(2) Plastik (cling film);

(3) Gelas plastik;

(4) Gelas ukur;

(5) Tinta hitam dan berbagai warna;

(6) Termometer alkohol / raksa;

(7) Statif; dan

(8) Stopwatch.

Eksperimen dilakukan dengan memanaskan air di dalam gelas plastik di bawah sinar matahari. Plastik dipakai untuk membungkus gelas plastik agar tidak terjadi penguapan. Tinta hitam digunakan untuk mewarnai air sehingga memiliki sifat menyerap panas, dan eksperimen selanjutnya Akan menggunakan warna-warna yang lain. Termometer ditempatkan sedemikian rupa sehingga dapat mengukur perubahan suhu air selama 30 menit dan dituliskan dalam grafik.

Eksperimen ini telah diujicoba pada dua tempat dan dua waktu yang berbeda dengan rincian sebagai berikut.

Tabel 1. Waktu dan Tepat Eksperimen

\begin{tabular}{lll}
\hline No. & \multicolumn{1}{c}{ Tempat } & \multicolumn{1}{c}{ Waktu } \\
\hline 1. & Bandung $\left(6^{\circ} 54^{\prime} 43^{\prime \prime} \mathrm{S}\right.$ & 24 Desember \\
& $107^{\circ} 36^{\prime} 35^{\prime}$ 'E) & $2014(10.00-$ \\
& & 11.00 WIB $)$ \\
2. & Jember $\left(8^{\circ} 10^{\prime} 113^{\prime \prime} \mathrm{S}\right.$ & 4 Juli 2018 \\
& $\left.113^{\circ} 42^{\prime} 8^{\prime \prime} \mathrm{E}\right)$ & $(10.00-11.00$ \\
& & WIB $)$ \\
\hline
\end{tabular}

Dua waktu dipilih untuk menandai perbedaan kondisi musim dan lokasi geografis yang relatif mencolok.

\section{HASIL DAN PEMBAHASAN}

Berdasarkan analisis terhadap berbagai referensi, teori yang mendasari eksperimen ini dapat dijelaskan sebagai berikut. Ketika memanaskan air, energi per satuan waktu $(P)$ yang diperlukan untuk menaikkan suhu air karena radiasi matahari yaitu:

$$
P=m c \frac{\Delta T}{t}
$$

$P$ bersatuan watt dan $\frac{\Delta T}{t}$ adalah perubahan suhu tiap detik yang didapatkan melalui grafik eksperimen. Selanjutnya akan didapatkan besaran yang disebut flux density, yakni daya radiasi per satuan luas. Flux density matahari yang diterima di permukaan bumi $(F)$ dirumuskan sebagai berikut (Karttunen, Kröger, Oja, Poutanen, \& Donner, 2016).

$$
F=\frac{P}{A}
$$

Dimana $A$ adalah luas permukaan gelas plastik yang diradiasi matahari secara vektoris. Ukuran $A$ dipengaruhi jarak zenith matahari, sudut deklinasi, dan kedudukan lintang daerah setempat (Shivalingaswamy \& Kagali, 2017).

Selanjutnya kita kenalkan besaran Luminosity $(L)$, yaitu total fluks yang melewati suatu permukaan yang melingkupi sumber radiasi. Konsep ini dapat dianalogikan seperti fluks medan listrik yang menembus permukaan Gauss. Luminosity menunjukkan karakter kecerahan bintang yang berharga spesifik dan tidak dipengaruhi oleh jarak (Herr \& Muratori, 2006). Luminosity matahari dirumuskan sebagai berikut.

$$
L=F\left(4 \pi R^{2}\right)
$$

Dimana $R$ adalah jarak matahari-bumi. Luminosity yang kita dapatkan ini dapat digunakan untuk mencari flux density pada permukaan matahari $\left(F_{\odot}\right)$.

$$
\begin{gathered}
L=F_{\odot}\left(4 \pi r_{\odot}{ }^{2}\right) \\
F_{\odot}=\frac{L}{4 \pi r_{\odot}{ }^{2}}
\end{gathered}
$$

Dimana $r_{\odot}$ adalah radius matahari. Apabila matahari dianggap sebagai suatu benda hitam, maka flux density yang dipancarkan oleh matahari dapat dirumuskan sebagai berikut.

$$
F_{\odot}=\sigma T^{4}
$$

Dengan mensubstitusikan persamaan (2), (3), (4), dan (5) ke persamaan (6), diperoleh hasil sebagai berikut.

$$
m c\left(\frac{\Delta T}{t}\right)\left(\frac{1}{A}\right)\left(\frac{R^{2}}{r_{\odot}^{2}}\right)=\sigma T^{4}
$$




$$
T=\sqrt[4]{\frac{m c\left(\frac{\Delta T}{t}\right)\left(\frac{1}{A}\right)\left(\frac{R^{2}}{r_{\odot}{ }^{2}}\right)}{\sigma}}
$$

$$
\begin{aligned}
& \text { dengan: } \\
T= & \text { suhu permukaan matahari } \\
m= & \text { massa air (diukur dalam volume } \\
& \text { bersatuan } \left.\mathrm{cm}^{3}\right) \\
c= & \text { kalor jenis air }\left(4,2 \mathrm{~J} / \mathrm{cm}^{3} \mathrm{C}\right) \\
R= & \text { jarak matahari-bumi }\left(1,5 \times 10^{11} \mathrm{~m}\right) \\
r_{\odot}= & \text { radius matahari }\left(7,0 \times 10^{8} \mathrm{~m}\right) \\
\sigma= & \text { konstanta Stefan }- \text { Boltzmann } \\
A= & \left(5,69 \times 10^{-8} \text { watt } / \mathrm{m}^{2} \mathrm{~K}^{4}\right) \\
& \text { luas permukaan gelas plastik } \\
& \text { dengan proyeksi zenith } 30^{\circ} \\
& \left(0,001667 \mathrm{~m}^{2}\right)
\end{aligned}
$$

Secara teori, suhu permukaan matahari sebesar $5778 \mathrm{~K}$ dan Luminosity matahari sebesar 3,846×1026 W (“Sun-Wikipedia," t.t.).

\section{Suhu Permukaan Matahari}

Perlu diketahui bahwa eksperimen yang memerlukan sinar matahari seperti ini dipengaruhi oleh kondisi cuaca lokasi percobaan. Pada akhir bulan Desember, wilayah Indonesia mengalami musim penghujan. Selain itu kota Bandung merupakan daerah dengan suhu udara yang relatif dingin dan lembab. Hal ini menyebabkan kondisi cuaca tidak menentu. Waktu percobaan pukul 10.00-11.00 dipilih dengan pertimbangan menghindari cuaca mendung di tengah hari. Selain itu, pada rentang waktu ini diperoleh panas matahari yang cukup.

Sementara pada bulan Juli, wilayah Indonesia mengalami musing kemarau. Selain itu, kota Jember merupakan daerah dengan suhu udara yang relatif panas dan kering. Waktu percobaan pukul 10.00-11.00 dipilih dengan pertimbangan menghindari cuaca mendung di tengah hari. Selain itu, pada rentang waktu ini diperoleh panas matahari yang cukup.

Waktu yang paling direkomendasikan untuk melakukan eksperimen ini ialah ketika matahari berada di zenith (tepat di atas) lokasi pengamatan sekitar pukul 12.00 siang. Dengan demikian arah datangnya sinar matahari tidak membentuk sudut dengan luasan media yang disinari. Syarat agar kondisi ini dapat dipenuhi ialah pada tanggal tersebut matahari memiliki sudut deklinasi yang sama dengan lintang lokasi pengamatan. Hal ini karena luas penyinaran matahari dipengaruhi oleh sudut deklinasinya (Martin \& Goswami, 2019).

Bila dipilih lokasi Bandung, maka eksperimen akan efektif bila dilakukan pada tanggal 4 Maret atau 11 Oktober. Sedangkan pada tanggal 24 Desember, sudut deklinasi matahari sebesar $-23^{\circ} 26^{\prime}$ sehingga matahari tidak akan berada di zenith saat tengah hari.

Bila dipilih lokasi Jember, maka eksperimen akan efektif bila dilakukan pada tanggal 28 Februari atau 15 Oktober. Sedangkan pada tanggal 4 Juli, sudut deklinasi matahari sebesar $+22^{\circ} 56^{\prime}$, sehingga matahari tidak akan berada di zenith saat tengah hari.

Ilustrasi gerakan relatif matahari di daerah di sekitar garis khatulistiwa dalam koordinat horizon digambarkan oleh Gambar 3 berikut ("Sun's path in the sky during Equinox if watching from equator?," t.t.)

Selanjutnya akan dipaparkan hasil eksperimen pada kedua tempat tersebut. Perubahan suhu air tiap detik ditampilkan dalam grafik Gambar 4 dan Gambar 5.

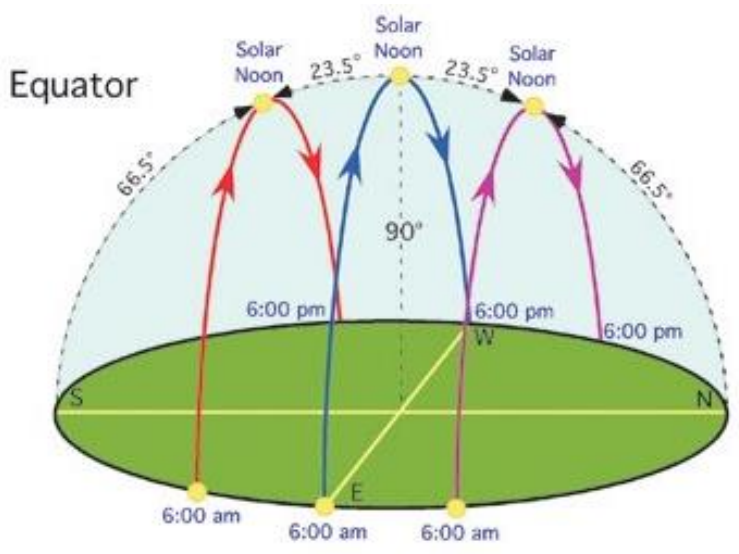

Gambar 3. Gerak semu matahari di sekitar khatulistiwa. Eksperimen ini akan efektif jika dilaksanakan ketika sudut deklinasi matahari tepat sama dengan letak lintang setempat 


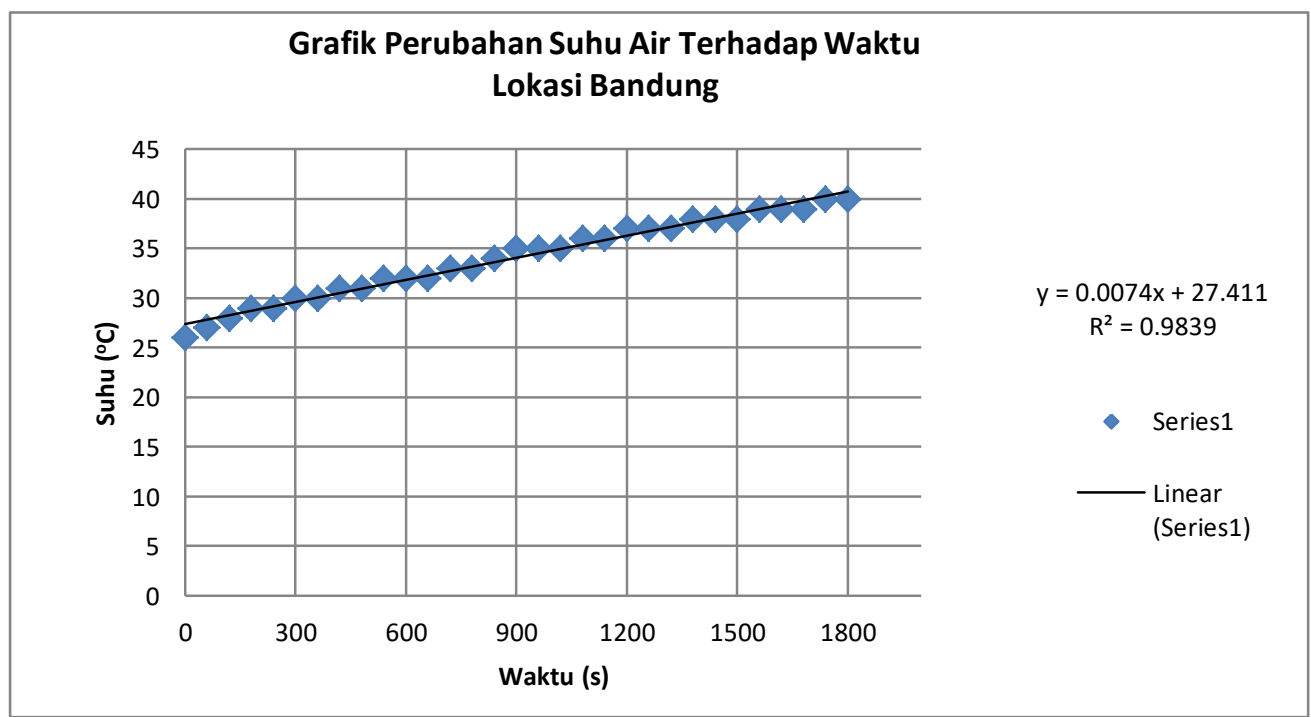

Gambar 4. Grafik perubahan suhu air Lokasi Bandung tanggal 24 Desember 2014 pukul 10.00-11.00 selama 30 menit.

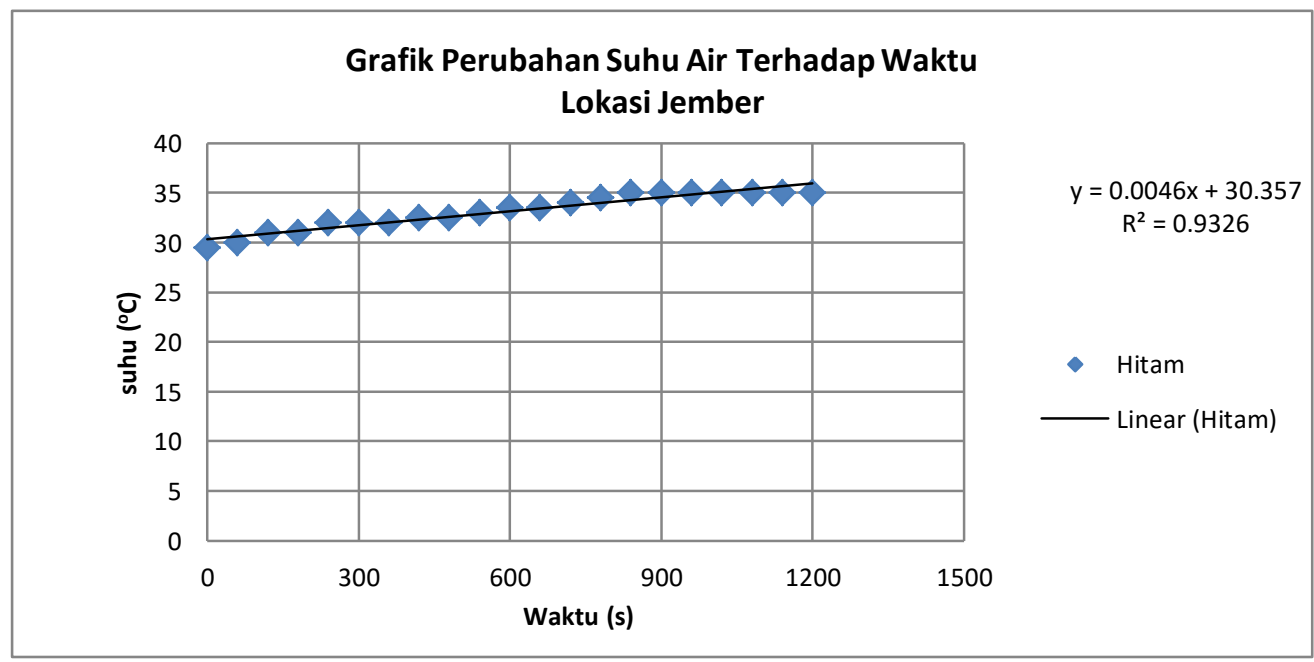

Gambar 5. Grafik perubahan suhu air Lokasi Jember tanggal 4 Juli 2018 pukul 10.00-11.00 selama 20 menit.

Eksperimen kedua tidak dilakukan selama 30 menit karena sampai pada menit ke 20 suhu air tetap tidak berubah.

Pada grafik tersebut didapatkan nilai koefisien regresi $\frac{\Delta T}{t}$ sebagaimana tertulis pada Tabel 2 berikut. Nilai ini penting untuk memperoleh nilai Luminosity matahari dan suhu permukaan matahari.

Selanjutnya, jika $\frac{\Delta T}{t}$ disubstitusikan pada persamaan (4) akan ditemukan perolehan nilai Luminosity matahari $(L)$ dan kesalahan $\left(\eta_{L}\right)$ yang dihasilkan dari referensi $\left(3,846 \times 10^{26} \mathrm{~W}\right)$.

Nilai Luminosity matahari yang diperoleh melalui eksperimen ini masih memiliki kesalahan yang besar, yakni di atas $10 \%$.
Selanjutnya, untuk menemukan suhu permukaan matahari, nilai $\frac{\Delta T}{t}$ yang diperoleh melalui eksperimen ini disubstitusikan ke persamaan (7) menghasilkan nilai seperti pada Tabel 3. Secara teori, suhu permukaan matahari sebesar $5778 \mathrm{~K}$.

Tabel 1. Waktu dan Tepat Eksperimen

\begin{tabular}{llccc}
\hline No. & Tempat & $\frac{\Delta \boldsymbol{T}}{\boldsymbol{t}}$ & $\begin{array}{c}\mathbf{L x 1 0}^{\mathbf{2 6}} \\
(\mathbf{W})\end{array}$ & $\boldsymbol{\eta}_{\boldsymbol{L}} \boldsymbol{\%}$ \\
\hline 1. & Bandung & 0,0074 & 5,27 & 37,2 \\
2. & Jember & 0,0046 & 3,25 & 15,3 \\
\hline
\end{tabular}

Karena nilai kesalahan kurang dari $10 \%$ hasil tersebut dapat diterima.

Pada hasil tersebut nilai Luminosity memiliki kesalahan yang lebih besar dari $10 \%$, 
sedangkan nilai suhu permukaan matahari memiliki kesalahan kurang dari $10 \%$. Perbedaan ini karena adanya pengaruh akar pangkat empat pada perumusan $T$ yang membuat perolehan $T$ mendekati teori.

Tabel 1 Hasil Perolehan Suhu Permukaan Matahari

\begin{tabular}{llccl}
\hline No & Tempat & $\frac{\Delta T}{t}$ & $T(\mathrm{~K})$ & $\eta_{L} \%$ \\
& & & \\
\hline 1 & Bandung & 0,0074 & 6219,78 & 7,12 \\
\hline 2 & Jember & 0,0046 & 5530,14 & 4,4 \\
\hline
\end{tabular}

Dengan demikian, jika nilai yang diterima harus memiliki kesalahan kurang dari $10 \%$, maka diperoleh batas bawah dan batas atas $\frac{\Delta T}{t}$ sebagai berikut.

Tabel 2 Batas Bawah dan Batas Atas Perubahan Suhu terhadap Waktu

\begin{tabular}{cccc}
\hline No & Batas & $T(\mathrm{~K})$ & $\frac{\Delta T}{t}$ \\
\hline 1 & Bawah & 5200,2 & 0,0036 \\
\hline 2 & Atas & 6355,8 & 0,0080 \\
\hline
\end{tabular}

Penjelasan diperolehnya nilai suhu permukaan matahari seperti di atas diduga karena masih ada waktu pada hari tersebut di mana matahari bersinar cukup terik dan tidak mendung. Alasan kedua, jika suhu lingkungan rendah, bagian yang menerima sinar matahari dapat merata di seluruh bagian air. Hal ini tidak dapat dihindari kecuali dengan menggunakan bahan yang terisolasi sempurna.

Hal lain yang menjadi diskusi ialah bagaimana hasil eksperimen ini bila dilakukan di daerah bermusim panas dibandingkan dengan eksperimen yang dilakukan di daerah tropis seperti ini. Telah diketahui bahwa daerah bermusim panas bisa memiliki suhu ekstrim antara $30^{\circ} \mathrm{C}-40^{\circ} \mathrm{C}$. Menurut pendapat menulis, pada eksperimen ini hanya dibutuhkan perubahan suhu tiap waktu, bukan mendapatkan suhu akhir eksperimen. Meskipun suhu akhir di daerah bermusim panas lebih tinggi daripada suhu akhir di daerah tropis, perubahan suhu tiap detiknya diprediksi relatif tidak jauh berbeda. Namun, diperlukan data empiris tambahan untuk menjelaskan hipotesis ini.

\section{Pengaruh Warna terhadap Perubahan Suhu}

Hasil eksperimen juga tidak lepas dari pengaruh pemberian warna hitam pada air. Pada percobaan yang kedua, penulis membuat variasi warna pada air sehingga menemukan warna yang paling berpengaruh terhadap peningkatan suhu akibat radiasi matahari. Eksperimen ini dilakukan dengan membandingkan 4 warna air: hitam, merah, hijau, ungu. Hasil yang diperoleh ditampilkan pada grafik pada Gambar 6 .

Pada Gambar 6, diketahui bahwa urutan peningkatan suhu mulai yang terbesar dimiliki oleh benda berwarna hitam, hijau/ungu, dan

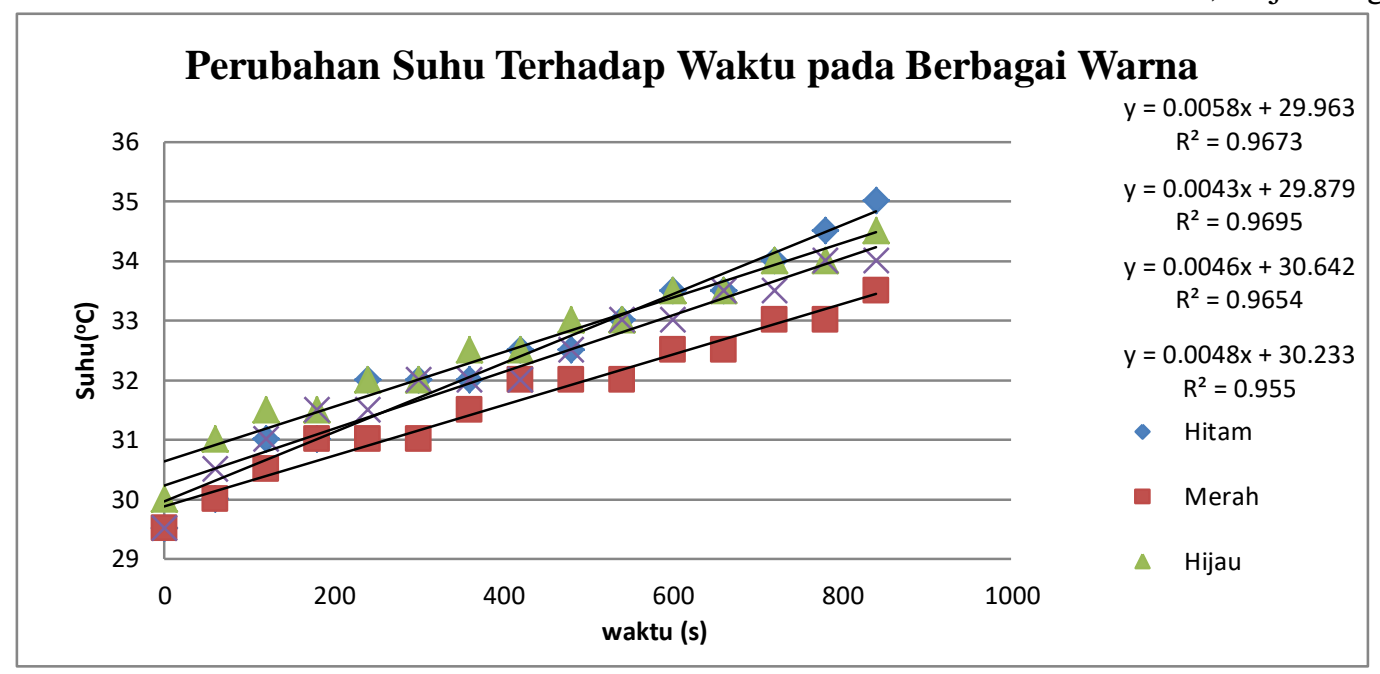

Gambar 6. Perubahan Suhu Terhadap Waktu

pada Benda Berwarna Hitam, Merah, Hijau, dan Ungu

tidak hanya permukaan air bagian atas, tetapi juga dinding gelas plastik yang menghadap matahari. Inilah menyebabkan panas matahari merah. Warna hitam menyerap seluruh spektrum dari cahaya putih tetapi tidak memantulkan energi. Konsekuensinya, warna 
hitam akan lebih cepat panas dan mencapai suhu tertinggi dari termometer lainnya. Hal ini juga berarti akan lebih cepat dingin ketika tidak ada sumber panas. Warna hitam memiliki perubahan suhu yang ekstrim karena dapat menyerap sebagian besar panas dalam waktu singkat, dan sama halnya, juga dapat melepaskan sebagian besar panas dalam waktu singkat.

Hasil eksperimen juga menunjukkan warna hijau dan ungu pun dapat menyerap dan memantulkan radiasi sehingga menjaga radiasi termal lebih lama dan menghangatkan area lebih cepat tetapi tidak sebaik warna hitam ("Radiation and Absorption in Colors | Antonio's Blog," t.t.).

Kalor dan cahaya merupakan dua jenis energi yang berbeda. Energi cahaya dapat diubah menjadi energi kalor. Benda yang berwarna hitam menyerap semua panjang gelombang dan mengubahnya menjadi kalor. Akibatnya benda jadi cepat panas. Benda yang berwarna putih memantulkan semua panjang gelombang sehingga cahaya tidak diubah menjadi kalor ("UCSB Science Line," t.t.).

Berkaitan dengan pengaruh warna pada permukaan yang diradiasi, sebuah warna akan menyerap semua panjang gelombang kecuali warna tersebut. Misalnya benda berwarna merah. Benda tersebut akan menyerap semua warna kecuali warna merah. Warna merah akan dipantulkan sehingga diterima oleh mata manusia. Kesimpulannya benda dengan warna yang berbeda akan menyerap kalor yang berbeda pula. Di sini, penulis merekomendasikan adanya percobaan lanjutan untuk mengetahui pengaruh warna yang lebih bervariasi, berikut tingkat cerah/gelapnya warna tersebut.

\section{Pembelajaran Pengayaan}

Pembelajaran pengayaan diberikan untuk mengakomodasi perbedaan siswa dengan strategi yang berazaskan maju berkelanjutan (continuous progress). Pembelajaran ini dipecah menjadi satuan-satuan (cremental units). Peserta didik yang mempelajari unit satuan pelajaran tertentu dapat berpindah ke unit satuan pelajaran berikutnya jika siswa yang bersangkutan telah menguasai sekurangkurangnya $75 \%$.

Pembelajaran pengayaan diberikan berdasarkan tes kecakapan dan ketuntasan. Materi yang diberikan sama atau bisa lebih kompleks. Pembelajaran pengayaan dapat dilakukan dengan pemberian materi tambahan atau berdiskusi yang bertujuan memperluas wawasan bagi KD tertentu; pemberian tugas analisis gambar, model, grafik, bacaan/paragraph, dan sebagainya; pemberian soal-soal latihan tambahan yang bersifat pengayaan; dan membantu guru membimbing teman-temannya yang belum mencapai ketuntasan (Marzuki, t.t.).

Sebagai bahan pengayaan, eksperimen pengukuran suhu matahari ini telah memenuhi unsur pemberian materi tambahan dan tugas analisis grafik untuk memperluas KD 3.8 dan 4.8 pada kurikulum SMA. Peserta didik dapat mengetahui dan mempraktikkan secara langsung. Peserta didik juga dapat memiliki konstruksi awal tentang hubungan yang kuat antara matematika, fisika, dan astronomi sebagai bekal menempuh pendidikan pada tahap yang lebih tinggi. Namun, apakah bahasan ini terdapat dalam level zona perkembangan proksimal (zone of proximal development/ZPD) peserta didik, banyak diskusi terkait dengan hal ini. Hal ini mengingat pembelajaran akan menjadi bermakna jika informasi yang dipelajari masih dalam jangkauan level kognitif peserta didik, atau yang disebut dengan ZPD tersebut (Santoso Yohanes, 2013).

Pembelajaran pengayaan diharapkan diberikan secara menantang, tidak membuat peserta didik tertekan karena mempelajari konsep-konsep yang berada di luar jangkauannya. Analisis juga menunjukkan penurunan persamaan (7) membutuhkan kemampuan matematika yang tinggi. Dengan demikian kemampuan matematika menjadi prasyarat utama untuk dapat diberikannya pengayaan ini. Jika hal ini tidak terpenuhi, pilihan yang dapat diberikan adalah eksperimen pengaruh warna terhadap perubahan suhu, hal ini lebih mudah dan relevan.

Di samping itu, hubungan antara konsepkonsep yang sudah dipelajari sebelumnya, yang mungkin diajarkan pada tingkat kelas yang berbeda, juga penting untuk dipahami siswa. Misalnya untuk menjangkau materi radiasi, peserta didik harus telah menguasai topik besaran dan satuan serta kalor dan perambatannya. Jika pertimbanganpertimbangan ini belum dipenuhi, maka pengayaan ini dapat dipilih untuk tidak diajarkan. 


\section{SIMPULAN}

Tulisan ini melaporkan suatu analisis awal tentang peluang pembelajaran pengayaan pada materi fisika SMA pada topik radiasi, yakni eksperimen pengukuran suhu permukaan matahari dengan peralatan yang sederhana.

Berdasarkan hasil analisis, pengukuran suhu permukaan matahari dapat dilakukan dengan mengukur perubahan suhu per satuan waktu pada air berwarna hitam yang dipanaskan di bawah sinar matahari. Hasil eksperimen yang dilakukan pada lokasi Bandung tanggal 24 Desember 2014 dan lokasi Jember tanggal 4 Juli 2018 mengkonfirmasi hal ini. Berturutturut dihasilkan nilai suhu permukaan matahari sebesar 6219,78 K dengan kesalahan 7,12\% dan 5530,14 $\mathrm{K}$ dengan kesalahan 4,2\%. Keduanya dapat diterima karena kesalahan kurang dari $10 \%$.

Hasil eksperimen juga menunjukkan bahwa warna berpengaruh terhadap peningkatan suhu air akibat radiasi. Eksperimen yang sama tetapi dengan variasi empat warna, yaitu hitam, hijau, ungu, dan merah, menunjukkan bahwa warna hitam memiliki hasil yang paling signifikan. Hal ini karena sifat warna hitam ialah menyerap panas secara sempurna. Penulis merekomendasikan adanya eksperimen lanjutan untuk mengetahui pengaruh warna dengan variasi yang lebih banyak berikut tingkat cerah/gelapnya warna tersebut.

Berdasarkan analisis, hasil eksperimen ini dapat dipertimbangan sebagai pengayaan materi radiasi di tingkat SMA. Namun, prasyarat-prasyarat yang harus dipenuhi antara lain peserta didik harus memiliki kemampuan matematika yang tinggi dan konstruksi awal yang kuat pada topik besaran dan satuan serta kalor dan perambatannya.

\section{DAFTAR PUSTAKA}

Bell, J. A. (1968). TPT NOTES: The temperature of the sun: A demonstration experiment. The Physics Teacher, 6(9), 466-467.

Biermann, M. L., Katz, D. M., Aho, R., DiazBarriga, James, \& Petron, Jerome. (2002). Wien's law and the temperature of the Sun. The Physics Teacher, 40(7), $398-400$.
Direktorat Pembinaan SMA. (2010). Juknis Pembelajaran Tuntas, Remedial, dan Pengayaan di SMA.

Dwiretnowati, E. (2012). Pengelolaan Program Pengayaan dalam Persiapan Menghadapi Ujian Nasional di SMP Negeri 1 Donorojo Pacitan. Universitas Muhammadiyah Surakarta.

Halliday, D., Resnick, R., \& Walker, J. (2013). Fundamentals of physics. John Wiley \& Sons.

Hera, R. (2018). $\quad$ STUDI KASUSPENGELOLAAN

LABORATORIUM SMA LAB SCHOOL UNIVERSITAS SYIAH KUALA BANDA ACEH. Bionatural: Jurnal Ilmiah Pendidikan Biologi, 4(1).

Herr, W., \& Muratori, B. (2006). Concept of luminosity.

Karttunen, H., Kröger, P., Oja, H., Poutanen, M., \& Donner, K. J. (2016). Fundamental astronomy. Springer.

Kementerian Pendidikan dan Kebudayaan. (2013). Kompetensi Dasar Sekolah Menengah Atas (SMA) / Madrasah Aliyah (MA).

Kerlin, A. B., DeSilva, L. A., Rose, S., \& Hasbun, J. E. (2016). Calculating the Sun's photospheric temperature, an undergraduate physics laboratory. Georgia Journal of Science, 74(2), 13.

Lee, W., Gilley, H. L., \& Caris, J. B. (1997). Finding the surface temperature of the Sun using a parked car. American Journal of Physics, 65(11), 1105-1109. https://doi.org/10.1119/1.18729

Marr, J. M., \& Wilkin, F. P. (2012). A better presentation of Planck's radiation law. American Journal of Physics, 80(5), 399405.

Martin, C. L., \& Goswami, D. Y. (2019). Solar energy pocket reference. Routledge.

Marzuki. (t.t.). Perencanaan Pembelajaran Remedi dan Pengayaan. Diambil dari http://staff.uny.ac.id/sites/default/files/lai n-lain/dr-marzuki-mag/30-ppt-drmarzuki-perancangan-pembelajaranremedi-dan-pengayaan-mapel-paicompatibility-mode.pdf

Mullan, D. J. (2009). Physics of the Sun: A first course. Chapman and Hall/CRC.

Nur, M. (2011). Fisika Plasma dan Aplikasinya. Badan Penerbit Undip. 
Perry, S. K. (1979). Measuring the sun's temperature. The Physics Teacher, 17(8), 531-533.

Pramana, W. D., \& Dewi, N. R. (2014). Pengembangan E-Book IPA Terpadu Tema Suhu dan Pengukuran untuk Menumbuhkan Kemandirian Belajar Siswa. Unnes Science Education Journal, $3(3)$.

Radiation and Absorption in Colors | Antonio's Blog. (t.t.). Diambil 4 Desember 2019, dari

https://sites.suffolk.edu/yhuang9/2013/12 /03/radiation-and-absorption-in-colors/

Rahayu, A. P., \& Hakim, L. (2016). Pengembangan Permainan Bingo Sebagai Media Pengayaan Mata Pelajaran Akuntansi Perusahaan Jasa SMK Negeri Di Surabaya. Jurnal Pendidikan Akuntansi (JPAK), 4(3).

Rofiah, A., Rustana, C. E., \& Nasbey, H. (2015). Pengembangan buku pengayaan pengetahuan berbasis kontekstual pada materi Optik. Prosiding Seminar Nasional Fisika (E-Journal), 4, SNF2015-II-1-4.

Santoso Yohanes, R. (2013). Teori Vygotsky dan implikasinya terhadap pembelajaran matematika. Widya Warta, 34(02).

Satterly, J. (1919). Radiation and the Temperature of the Sun. Journal of the Royal Astronomical Society of Canada, 13,33 .

Shivalingaswamy, T., \& Kagali, B. A. (2017). Determination of the Declination of the Sun on a Given Day. European Journal of Physics Education, 3(1), 17-22.

Solar_Spectrum.png $(800 \times 595)$. (t.t.). Diambil 2 Desember 2019, dari https://upload.wikimedia.org/wikipedia/c ommons/4/4c/Solar Spectrum.png

Sun's path in the sky during Equinox if watching from equator? (t.t.). Diambil 3 Desember 2019, dari Physics Forums | Science Articles, Homework Help, Discussion website: https://www.physicsforums.com/threads/ suns-path-in-the-sky-during-equinox-ifwatching-from-equator.660867/

Sun-Wikipedia. (t.t.). Diambil 2 Desember 2019, dari https://en.wikipedia.org/wiki/Sun

UCSB Science Line. (t.t.). Diambil 4 Desember 2019 , http://scienceline.ucsb.edu/getkey.php?ke $\mathrm{y}=3873$

\section{PROFIL SINGKAT}

Dinar Maftukh Fajar, S.Pd., M.Pfis merupakan dosen pada program studi Tadris IPA IAIN Jember. Sehari-hari mengampu mata kuliah Fisika Dasar, Bumi dan Antariksa, Mekanika, Gelombang dan Optik, Listrik Magnet, dan Sains, Teknologi, dan Masyarakat. Topik penelitian yang digelutinya adalah seputar pendidikan fisika, pendidikan sains, integrasi keilmuan, dan isu-isu lain yang berkaitan.

Indi Ghozirur Rohmah merupakan mahasiswa pada program studi Tadris IPA IAIN Jember. Penelitian yang sedang digelutinya berkaitan tentang pengembahan bahan ajar IPA Terpadu berbasis proyek. 